\title{
Securitization and Insurance - Characteristics of Hannover Re's Approach
}

\author{
Wilhelm Zeller \\ Hannover Re, Karl-Wiechert-Allee 50, Hannover 30625, Germany. \\ E-mail: wilhelm.zeller@hannover-re.com
}

Beginning with the first-ever (re)insurance risk securitization, Hannover Re's KOVER transaction back in 1994, the history of using capital market instruments for reinsurance risks at Hannover Re is shown in detail. This includes several non-life and life transactions as well as a more recent cover for the credit risk from reinsurance recoverables. Rationales and challenges for the altogether 15 capital market transactions are discussed very openly and an indication of a "promising future" is given.

The Geneva Papers (2008) 33, 7-11. doi:10.1057/palgrave.gpp.2510166

Keywords: securitization; insurance-linked securities; risk mitigation; catastrophe bonds; reinsurance; capital management

\section{Non-Life - Hannover Re's K Transactions}

Although most early non-life securitizations were principally focussed on transferring volatility to the capital markets in the form of catastrophe bonds covering discrete perils, Hannover Re's approach to securitization and the use of capital markets was motivated more from the perspective of capital efficiency and balance sheet management.

To understand the reasoning behind Hannover Re's "somewhat different" approach, one must recall that in late 1993/early 1994 Hannover Re was a wholly owned subsidiary of a German mutual insurance group. Thus, it was capital constrained at a time when the reinsurance markets were short of capacity and new capital was flowing into the newly formed Bermuda vehicles. Not wanting to pass up on the opportunities that the market offered, Hannover Re sought alternative forms of capital to leverage its existing underwriting platform and optimize its return without significantly increasing the risk to shareholders. Hannover Re developed a new approach, transferring reinsurance risk (quota-share retrocession of a defined portfolio) to a special-purpose company financed through the issuance of debt instruments where the performance of the investment was a floating-rate Libor return plus a participation in the underlying portfolio's underwriting return. In extreme cases, the principal was exposed to insurance risk should premiums not be sufficient to cover costs and expected losses.

This transaction, known as KOVER, represented a novel approach - formation of a special-purpose re-insurance company financed by insurance-linked notes - that became the model for what is today the standard structure of most reinsurance securitizations. The volume of investors' capital raised through KOVER was USD 85 million. 
In subsequent years, Hannover Re continued to experiment and innovate in the field of securitization of insurance risk. In 1994, it launched K2 (USD 100 million), the world's first portfolio-linked swap using ISDA standard documentation. K2 also broadened the scope of risks transferred to the capital markets by including aviation catastrophe risk in addition to property perils for defined peril regions.

As another innovation an option for issuing further USD 50 million of $\mathrm{K} 2$ - called $\mathrm{K} 2+-$ was purchased in 1998. This option - a "derivative on a derivative" - was exercised 2 years later.

Seeking to further improve the efficiency and reduce costs associated with the issuance of new instruments, Hannover Re moved to the use of a segregated accounts company, Kaith Re, in 2002 for its third portfolio-linked securitization, K3. This USD 230 million facility was tiered to a probabilistic assessment of the aggregated exposures. In order to assist the targeted AA rating, the required capital was calculated at the 99.98 per cent VaR level for the entire portfolio. Investors' share consequently was the percentage USD 230 million represented of the total capital required. In 2005, K3 was replaced by a USD 225 million instrument called C1 but using virtually the same conceptual approach.

Kaith Re was subsequently employed for the K5 and Kepler Re transactions in 2006 and 2007. The K5 transaction also added a further risk, marine excess of loss, to the range of risks transferred to capital market investors. With USD 530 million, capital committed by investors K5 also represents the largest transaction so far.

For the European windstorm risk, the USD 150 million Eurus bond was sponsored in 2006. All eight non-life transactions since 1994 totalled a securitization volume of USD 1.65 billion.

While the procedure meanwhile has become somewhat more "routine", there are still considerable transaction costs involved in this type of transactions that require about USD 100 million as a minimum volume to make it economically viable.

\section{Life - Hannover Re's L Series}

Similar to non-life, Hannover Re's motivation for securitizing elements of its assumed life portfolio was predominantly driven by balance sheet management considerations. At the time of its first life securitization, L1, Hannover Re accounted for its business in accordance with the German Commercial Code, which did not allow for the establishment of a balance sheet asset covering acquisition costs similar to DAC under U.S. GAAP or IFRS standards. This resulted in Hannover Re experiencing quite significant accounting strain in its profit and loss statement through the expensing of acquisition cost. The rapid growth of its assumed life portfolio also consumed significant cash resources. Through the securitization of its acquisition costs, Hannover Re was able to secure accounting relief and liquidity by monetizing this off-balance sheet asset. A further element of risk management was introduced through the L3 transaction, which was a multi-currency facility for emerging Asian insurance markets that helped Hannover Re to hedge exchangerate risk by sourcing the funds for the funding of new business in the original currency. 
With the adoption of IFRS, the accounting-driven motivation for using securitization disappeared; however, Hannover Re continued to employ securitization as an instrument to recycle liquidity by monetizing its embedded value asset through its most recent L6 transaction concluded in December 2005. An added benefit of using capital markets to monetize such intangible assets is that the pricing offered by capital markets also serves as an internal benchmark for valuing the remaining asset still on the company's books.

\section{Merlin - Using Capital Market Structures to Quantify Counterparty Credit Risk}

A growing concern among many users of reinsurance is the capital charge levied by the rating agencies (and, in future, by regulators following the adoption of Solvency II) for the counterparty risk assumed through such transactions. By adopting a layered or "tranched" structure commonly applied in many asset-backed transactions towards its unsecured reinsurance asset, Hannover Re was able to hedge over $€ 1$ billion in reinsurance recoverables through the placement of some $€ 95$ million in credit default notes. As the most senior tranche of the credit default protection already achieved a rating of AAA from Standard \& Poor's, the "super senior" tranche retained by Hannover Re representing some $€ 850$ million in assets no longer presented a credit risk to the company from a ratings perspective.

\section{Structure - Indemnity versus Index Trigger}

Hannover Re's early non-life securitizations relied on indemnity-based triggers. The reasons for this are that the portfolios placed with the capital market investors included perils and regions where modelling was not yet commonplace or, as in the case of K2 and K5, covered perils (aviation liability and marine hull) where no standard accepted model existed. That is not to say that modelling did not take place or that Hannover Re did not assume any basis risk. The portfolios were modelled stochastically and, where possible, also full density curves were generated. Where Hannover Re assumed basis risk was through the risk that the modelled capital requirements developed to support the securitized portfolio to a given probability of ruin proved inadequate.

From a sponsor's perspective, the indemnity nature of the securitization makes the accounting as well as rating and regulatory capital treatment simpler. For the investor, a more thorough understanding of the underlying portfolio dynamics as well as faith in the underwriting and modelling capabilities of the sponsor is required. This is perhaps why Hannover Re's K transactions remain unique within the securitization marketplace - only a handful of professional reinsurers may actually have the data and track record that would entice capital market investors to support such a structure.

The non-life structures utilized by Hannover Re were by nature designed to perform more as equity substitutes than as simple extreme catastrophe protections. Therefore, from a risk/return perspective they appealed more to the private equity-type investor than the typical high-yield fixed income investor. 
The evolution of standardized products relying upon industry loss or modelled and parametric loss triggers has helped to develop a broader and deeper market for catastrophe bonds providing discrete protection against extreme events. This development, coupled with the virtual collapse of the traditional retrocession market in 2006 led to a situation where insurance-linked securities in the form of catastrophe bonds for the first time became reasonably competitive to the remaining existing traditional markets. In the summer of 2006, Hannover Re placed Eurus, a USD150 million bond, utilizing a parametric index for protection against its European windstorm risk.

The life securitizations, whether for the financing of acquisition costs or monetizing embedded value, are by nature indemnity covers as the performance of the investment is directly linked to the underwriting risks (persistency and mortality) within the underlying portfolios.

\section{Resources - Infrastructure and Partners}

While transaction expenses have come down over the years, it is still a project-type task to issue a securitization rather than a routine transaction. The first work step is the allocation of dedicated human resources from various internal and external expert fields to a project team under the leadership of a more or less "full time coordinator", who will also be responsible for coordinating the massive information flow and the check-points on the time table.

Internal resources from the "sponsor" typically include:

- modelling experts for the probabilistic assessment of the business to be covered;

- legal experts for supervising the overall legal activities;

- asset managers for setting up the required capital market instruments (e.g. trust funds, note structure);

- in addition, it might be helpful to include accounting specialists for structuring special-purpose vehicles and taking care of solidation requirements; and

- retrocession experts for drafting the necessary retrocession documents between the sponsor and SPV (typically necessary if the sponsor is a reinsurer).

As most of the sponsors do not carry a full network of capital market services and resources, the following external resources are typically used:

- investment banks for transforming the deal structure into a marketable capital market instrument and approaching the investor community;

- external modelling agencies for giving an independent opinion on the risk;

- rating agencies (if desired) that will have their rating most probably on the external modelling agencies' opinion;

- legal professionals for drafting the necessary documentation (which in case of private placements can still be a massive and expensive procedure with tons of papers filled with several drafts);

- administrators for running SPVs; 
and, last but not least, auditors who should give their opinion on possible accounting implications in advance to avoid unpleasant surprises when the "hard" accounting procedure has to be executed.

\section{Challenges to Market Growth}

Already before the 2005 hurricane series, the most activity in securitized perils was for "peak perils" like U.S. hurricane, U.S. earthquake, European windstorm and Japanese earthquake. The reason is very straightforward: peak perils are consuming far higher capital contributions than average perils in (re)insurers' capital models. As a consequence, the pricing for peak perils is also far more "attractive" from an investor's standpoint - at least for single peril securitizations.

What the market is still missing are real diversification opportunities. There is a need for new products and for more standardization, for example, by using standardized indices rather than insurance expertise.

Also, there appears to be still "a handful of experts" driving the development. More talents and broader market expertise are needed to support market development.

The predominant risk securitized to date is event-driven risk. The often binary structure bears a greater potential for volatility simply because of the assessment risk.

The focus is on capital relief through risk transfer, especially for peak perils. Changing the focus to capital efficiency where more frequency rather than severity is the problem might offer significant future opportunities. This holds for non-life (e.g. motor, credit) as well as for life (embedded value, extreme mortality, reserve relief).

On the other hand, this would still require substantial knowledge of how insurance risks are composed and assessed with all parties involved in such transactions: $(\mathrm{Re})$ insurers, investors, modellers, investment banks and brokers. To simplify communication and understand the risk, it might be helpful to have accepted independent and proven indices for different risk categories available.

Finally, it is essential that the full relief from securitized transactions is accepted by regulators and rating agencies without artificial haircuts or formal constraints. Only a full reflection of the economic effects on both sides, issuers and investors, will fuel the market and encourage active players to spend resources in further developments.

\section{About the Author}

Wilhelm Zeller is Chairman of the Executive Board of Hannover Re. 